\title{
A PRACTICAL SOLUTION TO THE PROBLEM OF EMPTY SINGULAR THOUGHT ${ }^{*}$
}

\section{Introduction}

This paper is about what I shall call 'the problem of empty singular thought'. In the broadest terms, the problem looks like this. Consider the thought $<$ The Northernmost town in Ontario has cold winters $>^{1}$. This is a 'descriptive' thought: a thought the thinking of which involves actual or potential grasp of a description, and which is about an object iff it is the description's satisfier. It is plausible that many of our thoughts about particulars are descriptive. But it is not plausible that all of them are. There are good arguments for the conclusion that we also have 'singular' thoughts: thoughts which are about objects directly, without descriptive mediation ${ }^{2}$. For example, consider perceptual demonstrative thoughts - thoughts made available by perceptual links with objects and standardly expressed using 'this' or 'that'. There are good arguments for taking these thoughts to be singular. And there are good arguments for the parallel claim about the thoughts we standardly express using proper names. But, on the face of things, there are commonplace examples where a subject's $<$ That is $\Phi>$ or $<\mathrm{NN}$ is $\Phi>$ thoughts fail to be about anything. And it is hard to see how a class of thoughts can be made available by 'direct' or 'unmediated' relations to the objects they are about if a member of the class may be available when it is about nothing.

I am going to propose a new solution to this old problem. I shall lay out the problem in more detail, then sketch the solution I have in mind.

Let us start with two examples of the kind that get the problem off the ground:

Case $1-A<$ that $>$-thought based on a perceptual link with a non-object

You are having an experience indistinguishable by you from an experience of a rectangular thing in the middle distance. You have no reason not to take your experience at face value. You form the belief you would express by saying 'That is rectangular'. In fact, your experience as of something rectangular is caused by a freak combination of a speck on your glasses, a far-off tree, and a building on the horizon.

Case 2 - Thoughts made available by grasp of an empty proper name

1970's BBC regulations forbad assignment of a scriptwriting credit to anyone other than a show's initial scriptwriters. So a last-minute change by someone outside the initial scriptwriting group could not be credited to the person who made it. Instead, the fact that such a change had been made would be indicated by adding 'David Agnew' - a name introduced for this purpose - to the list of contributors to the script. Seeing 'David Agnew' appear repeatedly in BBC credits from this era, and ignorant of the story behind the name, you ask X, whom you have always found a reliable informant, and whom you know to have worked at the BBC in the 1970's, whether he knew David Agnew. X says 'Yes', and provides you with a range of details. You end up with beliefs you would express by saying things like 'David Agnew was from Bristol'; 'David Agnew was an old Etonian'; 'David Agnew was about 60 in 1975'.

Here are two at least initially plausible claims about these examples:

${ }^{1}$ I use pointy brackets to form names for propositions and propositional constituents.

${ }^{2}$ In adopting this definition I am picking up one strand in traditional and contemporary debates about singular thought. Other definitions, upon which I cast no aspersions, pick up other strands. See Jeshion 2010; Recanati 2010 for summaries. 
1 Neither your $<$ That is rectangular $>$ belief nor your $<$ David Agnew was an old Etonian $>$ belief is about any object.

2 Both your $<$ That is rectangular $>$ belief and your $<$ David Agnew was an old Etonian $>$ belief are justified.

$\mathbf{1}$ and $\mathbf{2}$ are consistent. But now let us add the following:

3 There is justification only where there is truth conditional content: if you are justified in believing that $<\alpha$ is $\Phi>$, there is a fact of the matter about what it would take for $<\alpha$ is $\Phi>$ to be true.

4 If there is a fact of the matter about what it would take for $\langle\alpha$ is $\Phi>$ to be true even though there is no object it is about, $<\alpha$ is $\Phi>$ is a descriptive thought.

A descriptive thought is true iff (a) its aboutness-fixing description is satisfied; and (b) this description's satisfier has the required property $(<$ The Northernmost town in Ontario has cold winters $>$ is true iff there is a unique northernmost town in Ontario, and this town has cold winters.) Given (a) and (b), a descriptive thought has truth conditions regardless of whether there is any object it is about. 4 is plausible because the descriptivist (a) + (b) model is the only viable model of how there might be a fact of the matter about what it would take for $<\alpha$ is $\Phi>$ to be true even though $<\alpha$ is $\Phi>$ is not about anything ${ }^{3}$.

$1-4$ entail that your $<$ That is rectangular $>$ and $<$ David Agnew was $\Phi>$ thoughts are descriptive: in each case, thinking the thought involves grasp of an aboutness-fixing description; the thoughts are not about anything because the aboutness-fixing descriptions are not satisfied.

But you can detect no difference in kind between thinking $<$ That is rectangular $>$ in Case 1 and thinking < That is rectangular $>$ in a situation where your experience as of something rectangular is based on a perceptual feed from a single object, so that this is the object your thought is about. Similarly, you can detect no difference in kind between thinking $<$ David Agnew was $\Phi>$ and thinking $<\mathrm{NN}$ was $\Phi>$ in a case where your $<\mathrm{NN}>$ thoughts are also all derived from reliable testimony, but these thoughts are about the bearer of ' $\mathrm{NN}$ '. In particular, you can detect no difference between the structure of your thoughts in the 'good' cases (where your thoughts are about objects) and the 'bad' cases (where, unbeknownst to you, aboutness fails). But, on the face of things, if there is a difference in structure between thoughts, this is a difference detectable by the subject. So, since you can detect no structural difference between the cases, there is no such difference. And if there is no structural difference between 'good' thoughts and 'bad' ones, it cannot be that 'bad' thoughts are descriptive and 'good' thoughts not. So we seem to have

\footnotetext{
3 I take views on which essaying an empty singular thought involves standing in a relation to a necessarily untrue 'gappy proposition' (Braun 2005; Garcia-Carpintero 2010) to involve denial that there is a fact of the matter about what it would take for the essayed thought to be true.
} 
5 If your thoughts in Case 1 and Case 2 are descriptive, all perceptual demonstrative thoughts and all thoughts made available by grasp of proper names are descriptive.

But there are good grounds for

6 Neither perceptual demonstrative thoughts nor proper-name-based thoughts are descriptive. Rather, these thoughts are singular - when you think a thought of one of these kinds about $o$, you stand in an aboutness-fixing relation to $o$ that does not involve grasp of a mediating description.

If $\mathbf{6}$ is true, one of $\mathbf{1}-\mathbf{5}$ must be false. But each of $\mathbf{1}-\mathbf{5}$ is initially plausible. So anyone who wants to keep $\mathbf{6}$ has a problem: Which of the initially plausible $\mathbf{1}-\mathbf{5}$ should be thrown away? I suggest that this formulation gets to the heart of why examples like Cases 1-2 have worried proponents of 6 . This is the version of the problem of empty singular thought that I shall concentrate on solving.

And here is the solution I am going to propose. Reject 3 - the claim that there is justification only where there is truth conditional content; keep everything else.

In a little more detail, I am going to argue that the possibility of rejecting 3 arises from the distinction between what I shall call 'classical' and 'practical' aboutness-fixing relations. If all aboutness-fixing were classical, we would be stuck with $\mathbf{3}$, and would need some other response to the problem of empty singular thought. But some aboutnessfixing is practical. And where aboutness-fixing is practical, 3 fails: if $\langle\alpha>$ 's aboutnessfixing mechanism is practical, a subject may be justified in believing that $\langle\alpha$ is $\Phi>$ even though $<\alpha$ is $\Phi>$ has no truth-conditional content.

To keep to a manageable length, I shall focus on the case of perceptual demonstrative thought (hereafter just 'demonstrative thought'). By the end of the paper I shall have established an account of aboutness-fixing for demonstrative thoughts according to which these thoughts are singular, and Case 1-type examples emerge as involving justification for beliefs that lack truth-conditions. Though I shall not protract the discussion by arguing for this claim, I am confident that a parallel solution, with suitable adjustments, can be given for the $\mathbf{1} \mathbf{- 6}$ problem as it arises for proper namebased thoughts. ${ }^{4}$ I take the fact that it applies to both empty demonstrative thoughts and empty proper name-based thoughts to be an advantage of the solution I am going to propose.

The rest of the paper is structured as follows. The next two sections develop the distinction between 'classical' and 'practical' aboutness-fixing relations. §4 sketches a practical account of perceptual demonstrative aboutness-fixing, and shows how this account solves the problem of empty singular thought. $\$ 5$ compares the practical account, and the practical solution to the problem of empty singular thought, with classical alternatives.

\footnotetext{
${ }^{4}$ Very roughly, the parallel solution requires replacing the notion of justification on the basis of perception (which is going to be central to the treatment of perceptual demonstratives) with the notion of justification on the basis of uptake from testimony. I develop this solution in forthcoming work.
} 


\section{\$2 Groundwork for the classical/practical distinction - Anscombe on speculative vs. practical knowledge ${ }^{5}$}

The distinction between 'classical' and 'practical' aboutness-fixing relations is most easily introduced as an extension of Anscombe's distinction between speculative and practical knowledge. This section gives a brief account of Anscombe's distinction. $\S 3$ uses Anscombian elements to develop a parallel distinction between kinds of aboutnessfixing relation.

As a first step towards Anscombe's distinction, consider the following example. Robin Hood and the Sheriff of Nottingham are shooting at a willow wand 250 yards away. Robin is an expert archer, easily able to hit willow wands at this distance in normal conditions. The Sheriff is a very poor archer, reliable only given a large, nearby target and no wind. Robin and the Sheriff both say 'I am going to hit that willow wand'. Each draws his bow, takes the most careful aim he can, and releases his arrow. Robin hits the willow wand. This is to be expected - he almost always hits his target, has hit willow wands at 250 yards many times before, and will do so many times again. The Sheriff also hits the willow wand. But the Sheriff very seldom hits his declared targets. This is the first time he has ever hit a target of anything like this size, or at anything like this distance. And, as it turns out, he will never replicate the feat as long as he lives.

Now consider the following question. Did each man, at the time when he released his arrow, know that he was going to hit the target?

In Robin's case, it is at least plausible that the answer is 'Yes'. His utterance stated his commitment to the claim that he was going to hit the target. So if we allow that a cognitive commitment of this kind is a belief, he believed that he was going to hit it. His belief turned out true. And it was not just lucky that it turned out true. Given Robin's skills and the conditions, he would have been very unlucky to miss. So Robin's claim 'I am going to hit that willow wand' looks like an expression of a true belief that is not just luckily true. And a true belief that is not just luckily true is at least a plausible candidate to count as knowledge.

In the Sheriff's case, things are different. We can suppose that the Sheriff is selfdeceived about his prowess, so believes that he is going to hit the target. His belief turns out true. But the Sheriff's skill is far below the level required to perform the feat at hand with any reliability. So the Sheriff's belief is merely luckily true. And lucky true belief is not knowledge.

Suppose we treat the initial statements in the example ('I am going to hit the target') as statements of intention. And suppose we take at face value the appearance that Robin's statement is a statement of knowledge while the Sheriff's is a statement of mere lucky true belief. Generalising from these suppositions yields two components of Anscombe's notion of practical knowledge. The first is the claim that intentions are a class of belief, or at least are belief-like in that they involve cognitive commitment to their propositional objects: intending to A (or intending to be A-ing) is having an attitude

\footnotetext{
${ }^{5}$ My interpretation of Anscombe in this section is indebted to Velleman 2007a xxi-Xxv and $2007 b$.
} 
that involves a cognitive commitment to A-ing. The second is the claim that fulfilled intentions can count as states of knowledge: if I intend to A (or intend to be A-ing), and I actually do A (or actually am A-ing), my intention counts as knowledge (knowledge that I will $\mathrm{A}$, or that I am A-ing) iff there is an appropriate relation between my intention and my A-ing. 6

The final component of Anscombe's notion of practical knowledge emerges when we compare the claim that intentions can count as knowledge to the cases that are central to mainstream epistemology. There is a sharp contrast between these standardly discussed cases and the kind of knowledge that we might claim to be constituted by fulfilled intention. The contrast concerns what we may call the 'orientation' of the relation that secures the difference between knowledge and mere lucky true belief.

In the cases on which mainstream epistemology focusses, this relation runs inwards, from world to mind: it secures the result that the belief conforms to the world. For example, according to standard reliabilism, a true belief counts as knowledge iff it is reliably caused by its truthmaker, or reliably caused by a factor reliably causally connected with its truthmaker. And on a counterfactual 'tracking' view a true belief counts as knowledge iff it is formed in such a way that whether or not the subject holds the belief depends counterfactually on whether or not it is (or will turn out to be) true (so that the counterfactuals 'If $\mathrm{p}, \mathrm{S}$ would believe that $\mathrm{p}$ ' and 'If not-p S would not believe that p' both hold).

Anscombe calls this kind of knowledge 'speculative knowledge': $\mathrm{S}$ has 'speculative knowledge' that $\mathrm{p}$ iff $\mathrm{S}$ believes that $\mathrm{p}, \mathrm{p}$ is true, and $\mathrm{S}$ 's formation of the belief that $\mathrm{p}$ depends on the fact that $\mathrm{p}$ (or some fact that determines that it will be the case that $p$ ) in an appropriate way. ${ }^{7}$

In the case of Robin's knowledge that he is going to hit the target, the orientation of the relation between belief and truthmaker is reversed. In this case, the status of the belief as more than just luckily true is not secured by a relation that runs inwards, from the truthmaker to the belief. It is secured by the role the belief plays in bringing about its truthmaker. Given Robin's skill, when he commits himself to hitting the target it is not just a matter of luck that this commitment ends up fulfilled. Rather, Robin's skill enables his intention to be a non-lucky generator of its fulfilment. In the Sheriff's case, in contrast, the fact that the intention ends up fulfilled is just a matter of luck. The Sheriff is cognitively committed to the claim that he will hit the target. But given his lack of skill, this commitment cannot play the role in bringing about its fulfilment that is required for an intention to count as knowledge. ${ }^{8}$

So whether an intention counts as knowledge does not depend on how it is formed. It depends on whether it plays an appropriate role in generating its fulfilment.

\footnotetext{
${ }^{6}$ See, for example, Anscombe's account of 'the knowledge that a man has of his intentional actions' at Intention 51-52. For the distinction between knowledge of action in intention and mere luckily fulfilled intention see the discussion surrounding Anscombe's claim that the connection between intention and action is not just a 'grace of fate' at 5153.

7 See Intention 87, and compare the discussion of 'contemplative' knowledge at 57.

${ }^{8}$ Compare Velleman 2007a xii-xv
} 
Some philosophers are squeamish about applying the term 'belief' to a state of this kind' To avoid terminological wrangling on this score, I shall step back from the claim that intentions are a class of belief, and say instead only that intentions are 'cognitive commitments'. With this qualification, the notion of practical knowledge can be introduced as follows ${ }^{10}$ :

I have 'practical knowledge' that I will A (or am A-ing) iff

i) I intend to A (or intend to be A-ing), so am cognitively committed to the claim that I will A (or am A-ing).

ii) My cognitive commitment turns out to be fulfilled (I will A or am A-ing).

iii) My commitment plays an appropriate luck-eliminating role in generating its fulfilment.

Note that (i)-(iii) leave open the question of exactly what role my intention to A must play in bringing about my A-ing if the intention is to count as practical knowledge. Different answers to this question generate different accounts of practical knowledge. For example, one possibility - a possibility which generates a reliabilist notion of practical knowledge - is that my intention to A counts as practical knowledge iff it is a reliable cause of my A-ing ${ }^{11}$. Another is a counterfactual view of practical knowledge: my intention to A counts as practical knowledge iff there is robust counterfactual dependence of my A-ing on my intention to A, so that both 'If I intended to A then I would A' and 'If I did not intend to A then I would not A' are true.

Note also that the account allows that in many (or even most) cases we have both practical knowledge of an intended action and speculative knowledge about it. In many cases of action, you observe both yourself moving and the effects of your movements: you see and feel your hand holding a piece of sandpaper and moving across a table-top; you see the of tip of your arrow line up with the target as you feel yourself pull the bowstring back. Given other premisses, these observations provide a route to speculative knowledge that that you are sanding the table or shooting at the target. But the fact that you have (or have available to you) speculative knowledge about your actions does nothing to undermine the fact that you also have practical knowledge of them. You may have speculative knowledge that you are A-ing, because you are observing yourself Aing. But you also have practical knowledge that you are A-ing which does not depend on

\footnotetext{
${ }^{9}$ For example, see Setiya 2008 400-401.

${ }^{10}$ Compare Anscombe Intention 57 ‘...there are two knowledge's - one by observation, the other in intention'; 87: 'Practical knowledge is "the cause of what it understands", unlike "speculative" knowledge, which is "derived from the objects known".' Anscombe is quoting Aquinas.

${ }^{11}$ Velleman says that Anscombe's own account of practical knowledge is reliabilist: 2007a xiv.
} 
observation: you know without observation that you are A-ing because you intend to A, you actually are A-ing, and your A-ing is appropriately generated by your intention. ${ }^{12}$

In what follows I shall argue that a 'good' case of demonstrative thought (a case where there is an object the thought is about) involves a form of practical knowledge. The mind has something like an intention to represent things outside itself. The informationprocessing that lies behind formation of demonstrative thoughts plays a role parallel to the role of Robin Hood's skill: it enables representational intention to generate its fulfilment in such a way that it counts as knowledge. A case of empty demonstrative thought is like a case of unluckily failed intention: a case where the subject does everything required for non-lucky A-ing, but the world does not cooperate (an earthquake moves the target; a passing seagull gets hit instead) and the intention goes unfulfilled.

But to develop this proposal properly I need to extend the notion of practical knowledge beyond its initial Anscombian setting. That is the task of the next section. (I make no suggestion that Anscombe herself would have endorsed the extensions I am about to propose.)

\section{$\S 3$ Classically vs. practically oriented thought about particulars}

This section extends Anscombe's distinction between speculative and practical knowledge into a distinction between what I shall call 'classical' and 'practical' aboutness-fixing relations. The section has three parts. The first distinguishes between what I shall call 'classical' and 'practical' accounts of how an initial segment of a process can set standards for the rest. The second uses examples involving descriptive aboutnessfixing to show how the distinction between classical and practical standard-setting might apply to thought about particulars. The third abstracts away from this initial descriptivist setting to give a general distinction between classical and practical aboutness-fixing relations. In outline, the suggestion is going to be that an aboutness-fixing relation sets standards for the formation of belief; classical aboutness-fixing involves one kind of standard-setting; practical aboutness-fixing involves another. ( $\$ 4$ will develop a practical account of perceptual demonstrative aboutness-fixing, and show how this account solves the problem of empty singular thought.)

\section{\$3.1 Classical vs. practical standard-setting}

Consider the following cases:

The Armageddon System - the Armageddon System is a computer programmed to aim and fire weapons. The first stage in an Armageddon cycle - the 'aiming' stage - selects the target, and (in selecting the

${ }^{12}$ Anscombe writes 'Normally someone doing or directing anything makes use of his senses, or of reports given him, the whole time.... His sense inform him of what is going on.... Thus in any operation we really can speak of two knowledge's - the account that one could give of what one was doing, without adverting to observation; and the account of what is happening at a given moment (say) to the material one is working on. The one is practical, the other speculative.' (88-89) 
target), determines the trajectory with which the projectile should be spewed forth; the rest of the cycle (the 'firing' part) consists in various steps involved in spewing forth the projectile with the required trajectory.

The Utopia System - the Utopia System is a computer programmed to deliver workable solutions to cities' urban planning problems. The first stage in a Utopia cycle is selection of a target city. The rest of the cycle involves locating the target city's urban planning problems and developing workable solutions to them.

Now suppose you are an engineer tasked with checking whether each system is working properly. In each case, you will probably start with a blunt question. Is the Armageddon System destroying the targets it selects? Is the Utopia System generating workable solutions to the most obvious problems of the cities it is trained on? But if you are doing your job competently, you will not rest with answers to these initial questions. For a 'Yes' answer to either question over the range of results you are likely to have access to does not indicate that the relevant system is working properly - it may be a mere matter of luck that the target was destroyed or the urban planning problems solved. If you want to know whether one of the systems is working properly, you need to be more sophisticated. Each system is of a kind where a cycle's initial segment (the 'aiming' part of an Armageddon cycle; the 'selection' part of a Utopia cycle) sets standards of good order for the rest. In each case, if you want to know whether the system is working properly, you need to ask whether the rest of the cycle meets the standards of good order that the initial segment determines. And this question brings out a central difference between the systems - a difference in how the 'standard setting' works.

Consider the Armageddon System first. In this case, the 'aiming' part of a cycle also selects a trajectory and force with which the projectile should be spewed forth (imagine that the turning of a single dial both brings the target into the cross-hairs and selects parameters for the spewing forth of the projectile). So the initial ('aiming') segment of an Armageddon cycle lays down a template for the remaining ('firing') part. The 'firing' part proceeds in good order if (i) it conforms to the template set by the 'aiming' part, and (ii) it is not just a matter of luck that the 'firing' part conforms to this template: given the way the system is working, it is reliably the case that the 'firing' proceeds according to the parameters the 'aiming' lays down.

Now consider the Utopia System. In this case, the initial ('selecting') part of a cycle does not lay down a template for the rest to follow. Instead, the 'selection' stage determines a goal - it determines which city's major urban planning problems are to be solved. It is then up to the computer to locate the problems and come up with the best solutions. In determining whether the main ('finding problems; generating solutions') part of the cycle is running as it should, we cannot go back and find parameters set at the initial ('selection') stage: the selection stage does not set this kind of parameter. Rather, we have to look at the various steps the computer takes, and ask whether they will lead, reliably, to location of urban planning problems and development of workable solutions.

The distinction between these two cases generalises into a distinction between two ways that the initial segment of a process might set standards of good order for the rest:

Classical standard-setting: the initial segment of a process lays down a template for the rest to follow; steps in the rest of the process are in good order iff they tend towards producing non-lucky conformity to the template. 
Practical standard-setting: the initial segment of a process determines a goal; steps in the rest of the process are in good order iff they tend towards the goal's non-lucky fulfilment.

The first kind of standard-setting has the orientation of Anscombe's speculative knowledge. The kind of good order required for a belief to count as speculative knowledge is a matter of non-lucky conformity: a belief counts as speculative knowledge iff it is in non-lucky conformity with the way the world is. Similarly, in a case of classical standard-setting, the initial segment of a process sets a template, and steps in the rest of the process are in good order iff they are in non-lucky conformity with this template. I call this 'classical' standard-setting to avoid stretching Anscombe's terminology too far, and to mark the dominance in the philosophical tradition of appeals to standards with this orientation.

I say that the second kind of standard-setting is 'practical' because the resulting standards have the orientation of Anscombe's practical knowledge. The kind of good order required for an intention to count as practical knowledge is a matter of non-lucky fulfilment of a goal. Similarly, in a case of practical standard-setting, the initial segment of a process sets a goal, and steps in the rest of the process are in good order iff they tend to generate this goal's non-lucky fulfilment.

\subsection{Two examples}

The step from the distinction between classical and practical standard-setting to a distinction between classical and practical aboutness-fixing is most easily introduced by comparing examples:

\section{Case 3 'Tremulous Hand'}

'Tremulous Hand' is used to refer to the otherwise unidentified author of around 50000 Thirteenth Century glosses in Medieval manuscripts. Palaeographical analysis provides very strong evidence that these glosses are the work of a single person with distinctive (tremulous and left-leaning) handwriting. All that is known about Tremulous Hand is what can be deduced from the glosses themselves. Scholars of Medieval manuscripts have used evidence derived from the glosses (evidence about where and when the glosses were written; the kind of person who would have had access to the manuscripts in these times and places; and so on) to build quite rich bodies of $<$ Tremulous Hand was $\Phi>$ beliefs.

Case 4: 'Casa Nostra'

You are participating in deliberations about house-buying. These deliberations involve weighing the interests of relevant parties - who would prefer to be able to walk to work; who likes to do what in his or her spare time; how serious an issue traffic noise is for everybody concerned. For convenience in the joint deliberations you have introduced a name, 'Casa Nostra', which you use to have conversations like the following: 'Maybe Casa Nostra should be in that neighbourhood so that you can walk to work.'; 'Well, this isn't Casa Nostra - it's right on this ugly intersection.' Eventually, if you are effective in your deliberations, you make a good purchase. 'Here it is' you say, as you move in - 'Casa Nostra at last'.

In each of these cases, a name is introduced using a reference-fixing description ('the author of these glosses'; 'the house we should buy'). In each case, the name's bearer (if it 
has one) is the satisfier of the description. ${ }^{13}$ And in each case, grasp of the description sets standards of good order for development of an associated body of beliefs. But the cases come apart with respect to how this standard-setting works.

Consider 'Tremulous Hand' first. In this case, grasp of the initial description provides a template for formation of justified $<$ Tremulous Hand $>$ beliefs: move to $<$ Tremulous Hand was $\Phi>$ given good reason to believe $<$ The author of the glosses was $\Phi>$. So, in terms of the distinction introduced in $\S 3.1$, the association between 'Tremulous Hand' and its reference-fixing description is a classical standard-setting relation: the stipulation that 'Tremulous Hand' is to refer to the author of the glosses establishes a template for formation of $<$ Tremulous Hand $>$ beliefs; the belief that $<$ Tremulous Hand was $\Phi>$ is in good order only if it is formed in non-lucky conformity to this template.

Now consider 'Casa Nostra'. In this case as described ${ }^{14}$, grasp of the initial description ('the house we should buy') does not lay down a template for formation of justified $<$ Casa Nostra is $\Phi>$ beliefs. Early in the decision-making process you have no idea of what it would take to satisfy this description. So you cannot try to build your body of $<$ Casa Nostra $>$ beliefs by holding the description up against the world looking for $<$ The house we should buy is $\Phi>$ truths. In this case, 'good order' for belief-forming moves does not involve intentional conformity to a recipe supplied by the initial description. Rather, it involves appropriate exercise of decision-making skill. If you are able to bring sufficient decision-making skill to bear, you will develop your body of $<$ Casa Nostra $>$ beliefs in such a way as to result in a right house-buying decision; a $<$ Casa Nostra $>$ belief is justified iff arrived at in a way that tends towards non-lucky generation of this result. This is 'practical' standard setting for belief-forming operations by grasp of a descriptive conceptual representation: grasp of the description determines a goal; you are maintaining your $<$ Casa Nostra is $\Phi>$ body of beliefs in good order iff you form only $<$ Casa Nostra is $\Phi>$ beliefs that tend towards non-lucky fulfilment of this goal.

These examples give a first indication of how Anscombe's speculative/ practical distinction extends into a contrast between kinds of aboutness-fixing relation. The last part of this section shows how to turn this initial, example-driven contrast into a general distinction.

\section{$\$ 3.3$ Classical vs. practical aboutness-fixing relations}

To establish the general distinction between classical and practical aboutnessfixing relations, let us start with the following principles, which I shall take, for the purposed of this discussion, to be foundational:

\footnotetext{
${ }^{13}$ Both 'Tremulous Hand' and 'Casa Nostra' are 'descriptive names'. Compare Evans $1982 \S 2.3$.

${ }^{14}$ An anonymous reviewer points out that you might start by engaging in meta-level research as to what is most likely to result in the flourishing of people like you, then treat the resulting (more detailed) description as a classical template. The reviewer is right, but that would be a different case.
} 
REFERENCE AND TRUTH - The belief that $<\alpha$ is $\Phi>$ is true iff the object $<\alpha>$ refers to is $\Phi$ (where $\Phi$ is the property represented by $<\Phi>$ ). ${ }^{15}$

(For example, the belief that $<$ Jack has fleas $>$ is true iff Jack has fleas; the belief that $<$ That is square $>$ is true iff the object $<$ that $>$ refers to is square; and so on.)

TRUTH AND JUSTIFICATION - Justification homes in on truth, so that, in general, the better your justification for a belief, the more likely it is that the belief is true. ${ }^{16}$

I shall argue that these two principles entail a third, which demands interpretation in terms of the claim that reference-fixing is the initial, standard-setting phase of beliefformation. The general distinction between classical and practical aboutness-fixing is a distinction between ways this standard-setting might work.

The third principle entailed by REFERENCE AND TRUTH and TRUTH AND JUSTIFICATION is

REFERENCE AND JUSTIFICATION $-<\alpha>$ refers to $o$ iff justification for believing that $<\alpha$ is $\Phi>$ homes in on getting $o$ 's properties right, so that, in general, the better the subject's justification for believing that $<\alpha$ is $\Phi>$, the more likely it is that $o$ is $\Phi$.

Given REFERENCE AND JUSTIFICATION, S's perceptual link with $o$ enables demonstrative thought about $o$ iff it makes $o$ the focus of justification for S's $<$ That is $\Phi>$ beliefs, so that, across the range of macroscopic observable properties $\Phi$ that $S$ is in the business of thinking about, if $\mathrm{S}$ forms only $<$ That is $\Phi>$ beliefs justified on the basis of the perceptual link, S will be unlucky if $o$ is not $\Phi$ and not merely lucky if it is. Put another way, S's perceptual link with $o$ enables demonstrative thought about $o$ iff it secures the truth of the following counterfactual: if $\mathrm{S}$ were justified on the basis of the perceptual link in believing things like $<$ That is square $>$, $<$ That is red $>$, and $<$ That is getting closer $>$, S would be unlucky if $o$ did not match these beliefs and not merely lucky if it did.

Here is (a short form of ${ }^{17}$ ) the argument from REFERENCE AND TRUTH and TRUTH AND JUSTIFICATION to REFERENCE AND JUSTIFICATION:

\footnotetext{
${ }^{15}$ I am taking it that a representation deployable in thought 'refers to' what it represents.

${ }^{16}$ For arguments for something like TRUTH AND JUSTIFICATION, see Velleman 2000; Boghossian 2005.

${ }^{17}$ There are two respects in which a long form of the derivation is more detailed. Firstly, the short form rests with the intuitive notions of justification 'homing in on' truth and 'homing in on' getting an object's properties right. The long form cashes out these intuitive notions in terms of the notion of a 'rationally relevant possibility'. (Roughly, the idea is that S's justification for the belief that $\mathrm{p}$ 'homes in on' truth iff it eliminates every rationally relevant possibility where $\mathrm{p}$ is not true, where the 'rationally relevant' possibilities are the possibilities $\mathrm{S}$ is rationally required to take into account before forming an opinion on $\mathrm{p}$. S's justification for the belief that $<\alpha$ is $\Phi>$ homes in on getting $o$ 's properties right iff it eliminates every rationally relevant possibility in which $o$ is not $\Phi$.) Secondly, the short form ignores the (arcane) possibility of what I call 'global
} 
1 Suppose (for reductio) that REFERENCE AND JUSTIFICATION is false. Then either (A) There are cases where $\langle\alpha>$ refers to $o$ but justification for believing that $<\alpha$ is $\Phi>$ does not home in on getting $o$ 's properties right; or

(B) There are cases where justification for believing that $<\alpha$ is $\Phi>$ homes in on getting $o$ 's properties right, but $\langle\alpha\rangle$ does not refer to $o$.

REFERENCE AND JUSTIFICATION is a biconditional. So if it is false, this is either because there are situations where its right hand side is true and its left false, or the other way around. (A) and (B) state these two possibilities. The rest of the argument shows that, given TRUTH AND JUSTIFICATON and REFERENCE AND TRUTH, both (A) and (B) can be ruled out, so the supposition that generates them must be rejected:

2 Consider a type-A case. This is a case where

(i) $\langle\alpha>$ refers to $o$, but

(ii) justification for believing that $\langle\alpha$ is $\Phi>$ does not home in on whether $o$ is $\Phi$.

Add REFERENCE AND TRUTH and TRUTH AND JUSTIFICATION:

(iii) $<\alpha$ is $\Phi>$ is true iff the referent of $\langle\alpha>$ is $\Phi$.

(iv) Justification for a belief homes in on whether the belief is true.

The combination of (i) and (iii) gives

(v) $<\alpha$ is $\Phi>$ is true iff $o$ is $\Phi$.

But (ii), (iv), and (v) are inconsistent. So there are no type-A cases.

3 Now consider a type-B case. This is a case where

(i) justification for believing that $<\alpha$ is $\Phi>$ homes in on what $o$ is like, but

(ii) $\langle\alpha>$ does not refer to $o$.

Add REFERENCE AND TRUTH:

(iii) $<\alpha$ is $\Phi>$ is true iff the referent of $\langle\alpha>$ is $\Phi$.

Putting (i), (ii), and (iii) together we get

(iv) S's justification for believing that $<\alpha$ is $\Phi>$ homes in on a condition that is not the condition for the truth of the belief.

However, given TRUTH AND JUSTIFICATION, we have

(v) The condition for a belief's truth just is the condition that justification for the belief (if it is available) homes in on.

And (iv) and (v) are inconsistent. So there are no type-B cases.

4 Given $\mathbf{2}$ and 3, we can reject the supposition at 1, and affirm REFERENCE AND JUSTIFICATION.

rational entanglement' - the possibility that, for all $\Phi$, S's possible justification for believing that $<\alpha$ is $\Phi>$ might home in on getting both $o$ 's properties right and $o^{*}$ 's properties right, for $o \neq o^{*}$. The need to address this possibility complicates step 3 (the consideration of type-B cases). 
But a belief-forming process runs to completion in good order (it produces a belief that the subject should be forming) only if it results in formation of a justified belief. ${ }^{18}$ So REFERENCE AND JUSTIFICATION can be reformulated as a claim connecting aboutness-fixing with good order for belief formation:

REFERENCE AND JUSTIFICATION (alternative version) - S's conceptual representation $<\alpha>$ refers to $o$ iff, in general, if S's $<\alpha$ is $\Phi>$ belief-forming processes were to run to completion in good order, they would tend towards getting $o$ 's properties right.

Now recall the distinction between classical and practical standard-setting from §3.1. In 'classical' standard-setting, the initial segment of a process sets a template for the rest to conform to. In 'practical' standard-setting, the initial segment sets a goal. Combining this contrast with the alternative version of REFERENCE AND JUSTIFICATION, we get the following distinction between classically and practically oriented thought about particulars:

Classically oriented thought about particulars $-\mathrm{S}$ 's $<\alpha$ is $\Phi>$-thoughts are 'classically oriented' thoughts about $o$ iff

(i) S's grasp of $\langle\alpha>$ sets a template for subsequent belief-forming moves, so that S's $<\alpha$ is $\Phi>$ beliefs would be in good order iff arrived at by moves conforming to this template; and

(ii) $<\alpha$ is $\Phi>$ beliefs that meet these standards will tend towards matching what $o$ is like.

Practically oriented thought about particulars - S's $<\alpha$ is $\Phi>$-thoughts are 'practically oriented' thoughts about $o$ iff

(i) S's grasp of $<\alpha>$ sets a goal for subsequent belief-forming moves, so that S's $<\alpha$ is $\Phi>$ beliefs would be in good order iff arrived at by means that tending towards fulfilment of this goal; and

(ii) $<\alpha$ is $\Phi>$ beliefs that meet these standards will tend towards matching what $o$ is like.

We have already seen the classical/practical distinction illustrated for the case of descriptive thoughts. The scholars' < Tremulous Hand $>$ thoughts are classically oriented thoughts about the satisfier (if there is one) of the description 'the author of these glosses'. Grasp of the description sets a template for formation of $<$ Tremulous Hand was $\Phi>$ beliefs; beliefs formed in conformity to this template will tend towards matching what the satisfier of the description (if there is one) is like. In contrast, your $<$ Casa Nostra $>$ thoughts are practically oriented thoughts about the house (if there is one) towards which good house-buying deliberations draw you. Your understanding of 'Casa Nostra' consists in adoption of a description as setting a goal for formation of $<$ Casa Nostra $>$ beliefs. Formation of a $<$ Casa Nostra is $\Phi>$ belief is in good order iff it tends towards non-lucky fulfilment of this goal.

The next section develops an account of demonstrative thoughts as practically oriented singular thoughts about particulars (an account, as I shall say, of "practical acquaintance') and shows how this account generates the solution to the problem of

${ }^{18}$ Again, compare Velleman 2000; Boghossian 2005. 
empty singular thought that I advertised in $\S 1$. The final section will compare this practical proposal with classical alternatives.

\section{$\S 4$ Practical acquaintance}

I shall present the 'practical acquaintance' proposal as an account of how two basic explanatory requirements on views of demonstrative thought are to be met. The first is that a view of demonstrative thought should enable us to explain how the $<$ That is $\Phi>$ beliefs we form by ordinary perception-based means are justified: these beliefs are justified; we should be able to explain how they are. The second is that a view of demonstrative thought should entail that, except in cases of reference failure, our demonstrative thoughts are about mind-independent objects. (There are extreme views that involve denying that our demonstrative thoughts are about mind-independent things, or denying that $<$ That is $\Phi>$ beliefs formed by ordinary means are justified. But it would take us too far afield to consider these extreme views here.)

The section is structured as follows. $\$ 4.1$ sets out an element that I suggest practical and classical views of demonstratives should share: a suitable appeal to empirical facts about perception. $\$ 4.2$ uses the account of practical aboutness-fixing from $\S 3$ and the empirical conclusion extracted from $\S 4.1$ to build an account of grasp of a demonstrative as practical acquaintance. $\S 4.3$ explains the practical solution to the problem of empty singular thought.

\section{\$4.1 The empirical basis of demonstrative thought}

An account of aboutness-fixing for demonstrative thought is an account of how perception enables us to think about things in the world. Such an account must be informed by relevant empirical facts about how perception works. But there is an evergrowing wealth of empirical findings about perception. So anyone wanting to develop an account of aboutness fixing for demonstrative thought faces an immediate question: Which empirical findings are relevant to this philosophical enterprise?

One advantage of the REFERENCE AND JUSTIFICATION-based framework outlined in $\S 3.3$ is that it generates an answer to this question. Given REFERENCE AND JUSTIFICATION, a perceptual link enables demonstrative thought about $o$ iff it secures that, in general, if $\mathrm{S}$ is justified in believing $<$ That is $\Phi>$ on the basis of the link, S will be unlucky if $o$ is not $\Phi$ and not merely lucky if it is. So the empirical story we are looking for will be at least a story about a reliable pathway from a perceptual link with an object to formation of $<$ That is $\Phi>$ beliefs: a pathway that will tend to deliver $<$ That is $\Phi>$ beliefs only if the object at the end of the perceptual link is $\Phi$.

It is obviously not possible to undertake an exhaustive investigation of this empirical story in a paper whose primary focus lies elsewhere. But it is possible to sketch as much of the story as we are going to need. ${ }^{19}$

${ }^{19}$ What follows draws on the discussion of perceptual 'constancy' and 'equivalence' in Palmer 1999 ch. 7. 
Let us start with a familiar example. Suppose you are watching a coin spin slowly in front of you. There is an intuitive sense in which the coin's shape 'looks different' as it turns: seen heads-on, the coin looks round; as it turns, it looks like a flatter and flatter ellipse, then a skinny rectangle, then an ellipse again. But there is also an intuitive sense in which the coin's shape appears unchanging: you seem to see a stably-shaped thing presenting different angles to you, not a thing whose shape is changing. And, in an ordinary circumstance, when you form a perception-based belief about the thing, it is the appearance of stability that prevails: you believe that the thing is a turning disc. (I shall use the terms 'feature-level appearance' to talk about the aspects of your experience that change in this kind of case, and 'property-level appearance' to talk about the aspects that remain the same: as you watch the coin, you experience a succession of changing featurelevel appearances and an unchanging property-level appearance. ${ }^{20}$ )

This example illustrates two fundamental aspects of the empirical story about our formation of perception-based $<$ That is $\Phi>$ beliefs.

The first is that our perceptual processing does not deliver just an array of featurelevel appearances which we must then think about how to bundle up into a world of objects and properties. If it did, your perceptual feed when you look at the coin would be restricted to feature-level appearances (the appearances of roundness, ellipticality, flatter ellipticality, and so on). Rather, our perceptual processing delivers an informational feed in which basic calculations from the two-dimensional array of features to properties attributed to things have already taken place. It is because your perceptual processing when you look at the coin includes these calculations that your experience seems like an experience of a stably-shaped thing presenting different angles to you.

The second aspect of the empirical story that the 'turning coin' case brings out is that our tendencies to form $<$ That is $\Phi>$ beliefs are keyed to property-level appearances rather than feature-level appearances Unless there is something unusual about the situation, you will form the belief you express by saying 'That is a spinning disc', rather than the beliefs you would express by saying 'That is round'; 'Now it's elliptical'; 'Now it's rectangular'.

The initial example brings out these aspects of the empirical story for the case of shape. But the same structure is replicated across the range of perception-based beliefs attributing observational properties. For example, as something moves away from you there is a sense in which it 'looks' smaller, but also a sense in which it 'looks' the same size. It 'looks' smaller in that it occupies a smaller proportion of your visual field. It 'looks' the same size because your perceptual processing takes note of 'depth cues' in your visual field to calculate its apparent distance, and calculates size properties by combining apparent distance with proportion of visual field. And, again, when it comes to forming < That is $\Phi>$ beliefs, your default tendency is to go with property-level information rather than mere feature-level information: you form the belief you would express by saying 'That is moving away', rather than the belief you would express by saying 'That is shrinking'. We could tell similar stories about property-from-feature calculations and the formation of $<$ That is $\Phi>$ beliefs for colour; motion; texture; and solidity.

${ }^{20}$ Compare the distinction between the 'proximal' and 'distal' modes of perception at Palmer 1999 p313. 
The connection between REFERENCE AND JUSTIFICATION and these aspects of the empirical story about formation of $<$ That is $\Phi>$ beliefs emerges when we add a basic observation. The pathway to $<$ That is $\Phi>$ belief that we have just described tends to deliver results that match what the object at the end of the perceptual link is like iff this object is an ordinary material object encountered in ordinary circumstances.

To see this, suppose you are looking at a strange object whose shape properties and reflectance-of-light properties are radically anomalous. This object starts out round, then, in the space of a few seconds, compresses into an ellipse, then into a skinnier ellipse, then into a flat rectangle, before expanding through shades of ellipticality back into a circle. Meanwhile, the object absorbs and reflects light in a non-standard way. The overall result is that the shape and orientation cues picked up by your visual system are the same cues as you pick up when you look at a turning coin. In this case, your visual system will make the same property calculations based on the same feature cues. But the $<$ That is $\Phi>$ beliefs you form based on these property calculations will not tend to get the object's properties right. Given this object's ways of behaving, your ordinary pathways to formation of $<$ That is $\Phi>$ beliefs will tend to generate beliefs that do not match its shape properties; if you end up with a $<$ That is $\Phi>$ belief that does match the thing's shape, this will be a matter of quite spectacular chance.

And, again, this observation generalises. The visual system uses a series of algorithms to calculate the perceptual property information that serves as input for formation of $<$ That is $\Phi>$ belief. These algorithms result in reliable belief formation only given perceptual encounters with objects that behave the way ordinary objects behave in ordinary circumstances.

The final aspect of the empirical story about formation of $<$ That is $\Phi>$ beliefs that will be relevant in what follows is the role of perceptual selective attention. 'Perceptual selective attention' is the process that highlights elements of perceptual input for additional processing. For example, consider your visual field as you look at this page. As you read, one cluster of words after another leaps out in more detail than the rest. At each moment, the part of your visual field that is being processed to this higher resolution is the part in the spotlight of your visual selective attention. ${ }^{21}$

Selective attention is selection for enhanced perceptual processing. And 'property from feature' calculations involve processing beyond the initial two-dimensional array of features. So it is to be expected that there will be a connection between these calculations and selective attention. And in fact there is solid empirical evidence for the conclusion that, though there are some 'property from feature' calculations outside the attentional spotlight, it is only within the spotlight that these calculations deliver rich property information with any reliability. ${ }^{22}$ (To get an intuitive grasp of this evidence, consider your experience of objects currently in your unattended peripheral vision. Imagine that you have just come into the room, and the objects are of unfamiliar kinds, so that you have only whatever information your unattended peripheral vision is giving you. Now suppose you are asked to say what the objects are like. You will probably be able to provide some basic information - that there is something dark coloured there; that there is something curved; that there is something else with sharp edges. And you will be better

${ }^{21}$ Compare Palmer 1999532.

${ }^{22}$ For a summary see 1999 554-563. 
than chance at 'binding' the more obvious features together (saying whether 'dark coloured' and 'sharp edges' apply to the same object). So your unattended perceptual processing is carrying out some 'property from cue' calculations. But it is carrying out only very basic calculations (there may seem to be a sharp-edged dark-coloured object in unattended peripheral vision; there will not seem to be something dark green and cubical; unattended perceptual processing cannot rise to that level of precision). And it is not carrying out these calculations very reliably: 'better than chance' performance is not reliable performance. It is only within the attentional spotlight that 'property from feature' calculations deliver either reliability or fineness of resolution.

Putting all these aspects of the empirical story together, we get what I shall call the 'empirical basis of demonstrative aboutness fixing':

The empirical basis of accounts of demonstrative aboutness-fixing $-<$ That is $\Phi>$ beliefs formed in the ordinary way in ordinary circumstances on the basis of an attentional perceptual link with an ordinary object will tend to match what the object is like.

To see why the empirical basis deserves its label, compare it with the following REFERENCE AND JUSTIFICATION-based characterisation of accounts of demonstrative aboutness-fixing:

An account of demonstrative aboutness-fixing will be an account of how the kind of perceptual link that enables demonstrative thought secures the result that a body of $<$ That is $\Phi>$ beliefs justified on the basis of this kind link with an object will tend to match what the object is like.

The empirical basis provides us with a not-yet-normative skeleton for the kind of account of demonstrative aboutness-fixing that REFERENCE AND JUSTIFICATION requires. So given the empirical basis, the problem of providing an account of demonstrative aboutnessfixing becomes the problem of closing the gap between the normative claim we want and the not-yet-normative skeleton for this claim that we already have. The distinction between practical and classical accounts of demonstrative thought is a distinction between views of how this gap should be closed.

\section{$\$ 4.2$ Demonstrative aboutness-fixing as practical acquaintance}

To get the account of demonstrative aboutness fixing as practical acquaintance on the table, let us go back to the general characterisation of practically oriented thought about particulars derived in $\$ 3.3$. Adapting this general characterisation to the specific case of demonstrative thought, we get the following:

S's $<$ That is $\Phi>$-thoughts are 'practically oriented' thoughts about $o$ iff

(i) S's grasp of $<$ that $>$ sets a goal for subsequent belief-forming moves, so that $S$ 's $<$ That is $\Phi>$ beliefs are in good order iff they are arrived at by means that tend towards fulfilment of this goal; and

(ii) if $\mathrm{S}$ makes only moves that are in good order relative to these standards, his or her $<$ That is $\Phi>$ beliefs will tend towards matching what $o$ is like. 
Different practical accounts of demonstrative thought will be generated by different accounts of how the goal-setting at (i) works.

There are ways to fill in the practical framework that will yield descriptivist practical proposals. For example, the claim might be that the goal-setting description for a demonstrative is 'the salient object'. According to this proposal, your goal when you form $<$ That is $\Phi>$ beliefs is that these beliefs be about the salient object. The description 'the salient object' plays a practical rather than classical standard-setting role because there is no saying in advance which object is salient; an object is made salient by the fact that a body of beliefs is being maintained in sensitivity to it.

The possibility of a non-descriptivist practical view (an account of perceptual demonstrative aboutness-fixing as practical acquaintance) emerges when we put a little pressure on the notion of a 'goal setting' mental state. So far I have been writing as if a goal-setting mental state is always an intention. But an intention is a propositional attitude: to have an intention is to intend to bring it about that $p$, where $p$ is a proposition specifying the intended outcome. So if a goal-setting mental state is always an intention, someone wanting to develop a practical account of perceptual demonstrative thought will be stuck with a descriptivist, or at least a conceptualist, proposal: a proposal according to which the goal-determining intention is $<$ I intend to represent the salient object $>$ or $<$ I intend to represent some thing outside the mind $>$.

But in fact there are good reasons to think that there is a family of goal-setting mental states that do not have propositional content. This is the family of basic psychological needs or compulsions. It is a familiar point that we have emotional needs and compulsions, for example, the need to avoid loneliness, and the compulsion to act aggressively. But having recognized emotional needs, it is hard to see grounds to resist the claim that there are also rational needs: needs we have in virtue of the fact that we are rational beings, and the having of some of which is constitutive of rationality. Some philosophers' accounts of our rational lives already appeal, explicitly or implicitly, to rational needs or compulsions: the need for knowledge ${ }^{23}$; the need to understand oneself $^{24}$; the need to avoid epistemic blame ${ }^{25}$; the compulsion to make basic inferential moves when presented with simple premisses ${ }^{26}$. I suggest that the need to represent is a basic rational need belonging to this same family: the mind has a basic need to represent things outside itself. This need sets the goal associated with an instance of perceptual demonstrative $<$ that $>$; $a<$ That is $\Phi>$ belief is justified iff it is formed by means that tend towards securing and sustaining representation.

A full defence of the practical proposal would go into more detail about the need to represent. But I am aiming to say just enough to establish the 'practical acquaintance' model as a contender in the debate about demonstrative aboutness-fixing, and show how

${ }^{23}$ Aristotle writes 'All men by nature desire to know.' (Metaphysics Book 1 part 1)

${ }^{24}$ Velleman 2000 20-24; 2007a xx.

${ }^{25}$ Boghossian says that the most basic inferences transmit warrant in virtue of instantiating epistemically 'blameless' patterns (2003 esp. 278-279). This account requires that basic inference is not itself a matter of thinking 'Pattern $\mathrm{X}$ is blameless; this step is in accord with pattern X; so I may take this step'.

${ }^{26}$ Peacocke 1992 6-8. 
it generates an alternative to extant (classical) solutions to the problem of empty singular thought. So, rather than pausing to defend the claim that we have a basic need to represent, or to say more about what this need is like, I shall adopt the claim as a supposition, and move on.

With the pieces now on the table, the 'practical acquaintance' model of demonstrative thought can be presented as follows.

Recall the explanatory requirements on a right account of demonstrative thought from the start of the section:

(a) An account of demonstrative thought should enable us to explain how the $<$ That is $\Phi>$ beliefs we form by ordinary perception-based means are justified (that is, we should take it that these beliefs are justified, but must be able to explain how they are).

(b) An account of demonstrative thought should entail that, except in cases of reference failure, our demonstrative thoughts are about mind-independent objects.

Now suppose a practical framework:

1 The mind has a basic need to represent things outside itself. Formation of a body of $<$ that $>$ beliefs in response to an attentional perceptual feed is a process selected by this need as a means to its fulfilment.

The 'practical acquaintance' account of demonstrative aboutness-fixing is an account of how this framework fulfils explanatory requirements (a) and (b).

Note first that, in general, a process selected by a motivational state runs to completion in good order iff it does so in a way that tends to generate the state's fulfilment, and a belief-forming process runs to completion in good order iff the resulting belief is justified. So we can move from 1 to

2 A $<$ that $>$ belief formed in response to an attentional perceptual feed is justified iff formed in a way that tends towards securing and sustaining the status of the $<$ that $>$ conceptual representation as referring to a thing outside the mind.

Now add REFERENCE AND JUSTIFICATION (3) and the empirical conclusion from $§ 4.1$ (4):

$3<\alpha>$ refers to $o$ iff, in general, justified $<\alpha$ is $\Phi>$ beliefs will tend to get $o$ 's properties right.

$4 \mathrm{~A}<$ That is $\Phi>$ belief formed on the basis of an attentional link by ordinary means tend to get the properties of the attended object right iff it is an ordinary object.

But recall that we are taking it that beliefs formed in this way are justified - the problem is to explain how they are (see the first explanatory requirement on $\mathrm{p}^{*}$ ). ${ }^{27}$ So we can combine the claim that the beliefs are justified with $\mathbf{4}$ to give

${ }^{27}$ In Dummett's terms, what is required is an 'explanatory justification' for the claim that these beliefs are justified, rather than a 'suasive justification', which would be an 
5 A $<$ That is $\Phi>$ belief formed in the ordinary way on the basis of perceptual link with an ordinary object is both a justified belief, and a belief formed in a way that tends to get the attended object's properties right.

5 and $\mathbf{3}$ entail

6 A $<$ That is $\Phi>$ belief formed in the ordinary way on the basis of an attentional link with an ordinary object is about the object.

With 6, we have met the second explanatory requirement - we have the result that, except in cases of reference failure, $\mathrm{a}<$ That is $\Phi>$ belief formed by ordinary means is about a thing outside the mind.

To deliver on the first explanatory requirement (the account of how $<$ That is $\Phi>$ beliefs are justified, think of what it is like keeping visual track of a 'thing' that is not an ordinary object, for example, a ripple moving across the surface of a lake or a raindrop running down a window. Attention can be drawn to such things without conceptual guidance (detection of motion is a very common attention-grabbing 'cue'). But most ripples and raindrops behave in ways that ordinary objects do not: ripples and raindrops move in ways that do not respect stable boundaries; they routinely split apart and fuse together with other ripples and raindrops; and so on. Most of the time, if your attention is caught by a 'thing' that is not an ordinary object, the visual object will display its nonordinary-objecthood almost immediately - before you have time to form a $<$ That is $\Phi>$ belief. And when non-ordinary-objecthood is displayed, you will either lose track of the thing (your attention will wander elsewhere) or you will begin to devote conceptual resources to tracking it. In the first kind of case, the attentional link is too short-lived for you to start essaying $<$ that $>$ beliefs. In the second, the result is a complex demonstrative thought $-<$ That ripple is moving fast $>$; $<$ That raindrop is reaching the bottom of the pane $>$ - rather than a simple demonstrative thought of form $<$ That is $\Phi>$. It is only where the ripple or raindrop (or reflection or shadow...) conceals its non-ordinariness that you will end up with a body of $<$ That is $\Phi>$ beliefs formed on the basis of an attentional link with a non-ordinary 'thing'. There are such cases. But they are vanishingly rare. claim:

But since such cases are rare, we can move from 6 to a corresponding reliability

7 Formation of $<$ That is $\Phi>$ beliefs in the ordinary way on the basis of attentional links is a reliable means of forming beliefs that are about things outside the mind.

Now 7 combines with 3 to give the practical explanation for the justification of $<$ That is $\Phi>$ beliefs formed by ordinary means:

argument for the claim that they are justified. For the 'suasive'/ 'explanatory' distinction see for example, Dummett 1978296. 
8 The $<$ That is $\Phi>$ beliefs that we form on the basis of attentional links in ordinary ways are justified because forming these beliefs is a reliable means to fulfilment of the mind's basic need to represent.

And that is the account of demonstrative aboutness-fixing that I want to propose. The last part of the section shows how this account generates a solution to the problem of empty singular thought.

(Note that $\mathbf{8}$ is an alternative to standard accounts of how perception justifies the simplest perception-based beliefs. But it would take us too far afield to consider in detail the possibilities for an account of propositional knowledge based on perception that this alternative account opens up.)

\section{$\S 4.3$ Practical acquaintance and the problem of empty singular thought}

Recall the problem of empty singular thought from $\S 1$, this time presented as an argument for the conclusion that demonstrative thoughts are not singular.

1 The $<$ That is $\Phi>$ belief formed in a case like Case 1 (where you form a $<$ That is $\Phi>$ belief on the basis of a perceptual link with a mereological gryphon consisting in parts of multiple distinct objects) is not about anything.

But

2 The belief formed in this case is justified.

However

$3 \mathrm{~S}$ can be justified in believing that $<\alpha$ is $\Phi>$ only if $<\alpha$ is $\Phi>$ has truth conditions.

And

4 If $<\alpha$ is $\Phi>$ has truth conditions even though there is nothing it is about, $<\alpha$ is $\Phi>$ is a descriptive thought.

But

5 If the thought in Case 1 is descriptive, all demonstrative thoughts are descriptive.

So

6 Demonstrative thoughts are descriptive, not singular.

In $\S 1$, I promised a response to this challenge that rejects $\mathbf{3}$ - the claim that there can be justification only where there are truth conditions. With the account of perceptual demonstrative reference fixing as practical acquaintance in place, I can now deliver on this promise. The 'practical acquaintance' model entails that in a Case 1 situation $\mathbf{1}$ and $\mathbf{2}$ 
are both true and $\mathbf{3}$ false: the subject is justified in forming a belief that has no truth conditional content.

Let us establish the 'no truth-conditional content' part of this claim first. The 'practical acquaintance' model entails that the subject's belief in a Case 1 situation has no truth conditions (there is no state of affairs that would make the belief true) because it entails that the truth conditions for a $<$ That is $\Phi>$ belief (if it has truth conditions) are determined by a relation to the object it is about: no object; no truth conditions. To get clear on this point, let us suppose that $\mathrm{S}$ is in a Case 1 situation, and try to assign truth conditions to S's beliefs. We can start with

(i) If S had been attending to an ordinary object and had formed a $<$ That is $\Phi>$ belief, S'S belief would have been true iff the attended object was $\Phi$.

But (i) will not sustain the move to

(ii) S's $<$ That is $\Phi>$ belief would have been true iff the attended object had been an ordinary object and that object had been $\Phi$.

For (ii) has to be read as something like

(iii) S's $<$ That is $\Phi>$ belief would have been true iff S's state of attending to a mereological gryphon had in fact been a state of attending to an ordinary object, and that object had been $\Phi$.

And (iii) is incoherent. A state of attending to something is a relational state. When you are attending to $o$, you are in the state of attending-to- $o$. If you had attended to something else, you would have been in a different attentional state. So instead of (iii) we have to say

(iv) If, in a situation indistinguishable by $\mathrm{S}$ from $\mathrm{S}$ 's actual situation, but involving attention to an ordinary object rather than a mereological gryphon, $\mathrm{S}$ had formed $\mathrm{a}<$ That is $\Phi>$ belief, this belief would have been true iff the attended ordinary object had been $\Phi$.

But (iv) is not an account of what it would take for the $<$ That is $\Phi>$ belief $S$ in fact forms on the basis of attention to the mereological gryphon to be true.

What about the 'justification' part of the claim? Here the point is just that the subject's position in a Case 1 situation is like Robin Hood's position in a situation where he takes a perfectly executed shot, but gets unlucky (an earthquake; a freak gust of wind...). In this case, Robin's movements as he aims and fires are still in normative good order because they are reliable generators of the fulfilment of the motivational state that lies behind them (the intention to hit the target). It is just that the world does not cooperate, so a pattern of movement that is in normative good order because it is a reliable generator of fulfilment of the motivational state that drives it is, happens, in this instance, to fail to deliver the usual result. Similarly, according to the 'practical acquaintance' model, $<$ That is $\Phi>$ beliefs formed on the basis of an attentional perceptual 
feed are justified because they are formed by a process that is a reliable generator of fulfilment of the motivational state that drives it - the mind's need to think about things outside itself. A case where there is no ordinary object at the other end of the attentional link is a case where the world is failing to cooperate, and a normally reliable method fails to produce the usual result.

The last section of the paper provides a brief comparison between this treatment of empty perceptual demonstrative thought and classical alternatives.

\section{Empty singular thought in a classical framework}

Recall the general account of classical aboutness-fixing from the end of $\S 3$ :

S's $<\alpha$ is $\Phi>$-thoughts are 'classically oriented' thoughts about $o$ iff

(i) S's grasp of $\langle\alpha>$ sets a template for subsequent belief-forming moves, so that $\mathrm{S}$ 's $<\alpha$ is $\Phi>$ beliefs are in good order iff arrived at by moves conforming to this template; and (ii) if S makes only moves that are in good order relative to these standards, $S$ 's $<\alpha$ is $\Phi>$ beliefs will tend towards matching what $o$ is like.

A classical account of demonstrative aboutness-fixing will treat our $<$ That is $\Phi>$ thoughts according to this general rubric, with differences between classical accounts resulting from different views about how the template-setting at (i) works.

For example, one suggestion - a suggestion that generates a classical descriptivist account of demonstrative thoughts - is that grasp of a demonstrative involves grasp of a descriptive condition, such as $<$ the cause of this experience ${ }^{28}$, which sets a template for formation of $<$ That is $\Phi>$ beliefs, so that justification for believing $<$ That is $\Phi>$ is derived from justification for believing $<$ The cause of this experience is $\Phi>$, and the aboutnessfixing story parallels the story we told for $<$ Tremulous Hand $>$.

An alternative suggestion, which yields an account of demonstrative aboutnessfixing as classical acquaintance, is to say that thinking a demonstrative thought involves standing in a relation to an object that lets the object itself provide the template for subsequent belief-forming operations. Very roughly, the idea here will be that attending to an object is like focussing a telescope. If a telescope is focussed on $o$, the telescope is working properly iff it delivers a stream of information that matches what $o$ is like, so $o$ provides the template to which the telescope's information-delivery processes must conform if they are to run to completion in good order. Similarly, according to a 'classical acquaintance' view, if you are forming $<$ That is $\Phi>$ beliefs on the basis of an attentional link with $o$, the information-processing that generates your beliefs is functioning in good order iff the beliefs it delivers match what $o$ is like. So, just as in the telescope case, $o$ itself is providing the template to which your $<$ That is $\Phi>$ beliefforming moves must conform if they are to be in good order. ${ }^{29}$

There are many variations on classical views that might be explored at this point. But I suggest that all variations face the same hard choice when it comes to cases where

${ }^{28}$ Compare Searle 1983.

${ }^{29}$ This is (roughly) the view in Campbell 2002. 
demonstrative reference fails. The hard choice is brought out by the following line of argument.

1 Suppose a classical framework for an account of demonstrative thought: grasp of a demonstrative establishes a template for formation of $<$ That is $\Phi>$ beliefs; $a<$ That is $\Phi>$ belief is justified iff formed in conformity to this template; the demonstrative refers to $o$ iff in forming beliefs in conformity to the template the subject will tend to get $o$ 's properties right.

Now consider a Case 1 situation - a situation where S believes $<$ That is $\Phi>$ on the basis of an attentional link with a mereological gryphon consisting in parts of a number of different things that S's visual system is being fooled into treating as a single ordinary object. Within the classical framework supposed at $\mathbf{1}$, we will have to say

2 In a Case 1 situation, either (i) S's attentional link establishes a template for formation of $<$ That is $\Phi>$ beliefs, or (ii) it does not.

3 If S's attentional link does not establish a template (option 2.ii), the classical framework entails that there is no account of what it would be for the process of $<$ That is $\Phi>$-belief formation to run to completion in good order. In that case, there are no standards of justification for S's $<$ That is $\Phi>$ belief, so the belief cannot count as justified.

4 If S's link with the mereological gryphon does establish a template (option 2.i), S's $<$ That is $\Phi>$ belief may be justified, but there is still a question as to whether it is about the attended 'thing'.

5 If S's belief is about the attended 'thing', the range of $<$ that $>$ thoughts includes not only thoughts about ordinary objects, but also about shadows, ripples, mereological gryphons, dots on screens, and any other 'thing' that can catch and hold attention.

6 If S's belief is not about the attended object, justification for a $<$ That is $\Phi>$ belief involves conformity to a template that can be in place even though there is no object that the belief is about. But if the template can be in place even though there is nothing the belief is about, it is not a template that is being provided by the object the belief is about itself. Rather, it must be a descriptive template: justification for a $<$ That is $\Phi>$ belief involves conformity to a descriptive template secured by the attentional channel; the belief is about something iff there is a thing that matches the template. But if justification for $<$ That is $\Phi>$ beliefs involves conformity to descriptive templates, $<$ That is $\Phi>$ thoughts are not singular.

So the classical framework forces a choice between the following three options: (A) Deny that our ordinary demonstrative thoughts are singular. (This is the view at 6.) (B) Deny that a Case 1 example is really a case of aboutness failure, that is, allow that every visual object that could potentially grab or hold our attention is a potential object of demonstrative reference. (This is the view at 5.) 
(C) Maintain that the subject's $<$ That is $\Phi>$ belief in a Case 1 situation is both empty and unjustified. (This is the view at 3.)

All three options are represented in the history of classical views of demonstrative thought ${ }^{30}$. But each is a hard pill to swallow.

(B) is hard to swallow because it sits uneasily with the traditional view of demonstratives as providing the basic subject matter of thought. According to this view, our grasp of the most basic kind of general thought (a thought like $<$ Something is square $>$ ) rests on our grasp of the potential reach of demonstrative aboutness-fixing, so that (roughly) understanding of 'Something is square' rests on knowing what it would be for $<$ That is square $>$ to be true for some potential instance of perceptual demonstrative 'that'. ${ }^{31}$ (B) combines with the traditional view to entail that all it takes for $<$ There is something square in the room $>$ to be true is for there to be some perspective from which some square visual object can grab attention. For example, $<$ There is something square in the room $>$ will come out true if no ordinary object is square, but there is some perspective from which a subject would be able to attend to a square mereological gryphon. I take it that this is at least a highly undesirable result.

(A) is hard to swallow because it involves giving up the traditional 'subject matter providing' view of demonstrative reference altogether, as well as rejecting every other argument for the claim that demonstrative thought is singular.

(C) is hard to swallow because it flies in the face of our intuitive view of Case 1type examples: the view that a $<$ That is $\Phi>$ belief in this kind of case may be justified even though there is nothing it is about.

I shall not protract the discussion further by exploring the various manoeuvres that someone working within a classical framework might make in the attempt to make (A), (B), or (C) more palatable. For my aim in this paper has been to establish the practical view as an alternative that will let us avoid both the hard decision and the manoeuvres that would have to accompany it.

\section{References}

Anscombe, G. E. M. Intention. Oxford: Blackwell. 1957.

Aristotle Metaphysics trans. W. D. Ross. Oxford: Clarendon Press. 1924.

Baldwin, Thomas 'Interpretations of Quantifiers', Mind 1975.

${ }^{30}$ For (A) see, for example, Russell The Philosophy of Logical Atomism; Dummett Frege Philosophy of Language; Searle Intentionality; Kaplan 'Quantifying In'. Campbell floats (B) in 'Does Visual Reference Depend on Sortal Classification'. For (C) see Campbell Reference and Consciousness.

31 Russell stated this view in terms of the claim that 'Something is square' really says 'The propositional function "... is square" gives value 'true' for some way of filling its argument place' $(1905 ; 1918)$. For more recent advocates of the view see, for example, Dummett 1973; Baldwin 1975. 
Boghossian, Paul. 'Is Meaning Normative?' in Boghossian Content and Justification. Oxford: Oxford University Press. 2008.

Boghossian, Paul. 'Blind Reasoning' in Boghossian Content and Justification.

Braun, David. 'Empty Names, Fictional Names, Mythical Names'. Nous 2005

Campbell, John. Reference and Consciousness. Oxford: Oxford University Press. 2002.

Campbell, John. 'Does Visual Reference Depend on Sortal Classification'. Philosophical Studies 2006.

Dummett, Michael. Frege: Philosophy of Language. London: Duckworth. 1973.

Dummett, Michael. 'The Justification of Deduction' in Dummett Truth and Other Enigmas. London: Duckworth 1978.

Evans, Gareth. The Varieties of Reference. Oxford: Oxford University Press. 1982.

Garcia-Carpintero, Manuel. ‘Fictional Singular Imaginings’ in Jeshion (ed.) 2010.

Jeshion, Robin (ed.) New Essays on Singular Thought. Oxford: Oxford University Press. 2010.

Jeshion, Robin. 'Singular Thought: Acquaintance, Semantic Instrumentalism, and Cognitivism' in Jeshion (ed.) 2010.

Palmer, Stephen. Vision Science: Photons to Phenomenology. Cambridge MA: MIT Press. 1999.

Peacocke, Christopher. A Study of Concepts. Cambridge MA: MIT Press. 1992.

Recanati, Francois. 'Singular Thought: In Defence of Acquaintance' in Jeshion (ed.) 2010.

Searle, John. Intentionality. Cambridge: Cambridge University Press. 1983.

Setiya, Keiran. 'Practical Knowledge'. Ethics 118. 2008.

Velleman, J. David. 'The Aim of Belief' in Velleman The Possibility of Practical Reason. Oxford: Clarendon Press. 2000.

Velleman, J. David. 'What Good is a Will?' in Anton Leist (ed.) Action in Context. Berlin: De Gruyter. 2007. 
Velleman, J. David. Practical Reflection. David Hume Series Edition. CSLI 2007.

* Acknowledgements - For conversations and correspondence which improved this paper, thanks to Dominic Alford-Duguid, Bill Brewer; John Campbell; Gary Ebbs; Robbie Howton; David Velleman; Barry Stroud; audiences at the 2008 Harvard Workshop on Singular Thought and the 2009 Barcelona Workshop on Singular Thought; my 2011 graduate class at the University of Toronto; and the editors of this volume. Michael Dummett died in December 2011 in the week this paper was taking its present form. I would also like to acknowledge the influence of his writings on my work on this and all related topics. 